\title{
IN-SITU RBS STUDIES OF STRONTIUM IMPLANTED GLASSY CARBON
}

\author{
O.S Odutemowo $^{1}{ }^{*}$, J.B Malherbe ${ }^{1}$, C.C Theron ${ }^{1}$, E.G Njoroge ${ }^{1}$, E. Wendler ${ }^{2}$ \\ ${ }^{1 .}$ Department of Physics, University of Pretoria, Pretoria, 0002, South Africa. \\ 2. Institut für Festkörperphysik, Friedrich-Schiller-Universität Jena, 07743 Jena, Germany.
}

\section{Highlights}

- Glassy carbon samples were implanted with $200 \mathrm{keV} \mathrm{Sr}$ ions at room temperature to a fluence of $1 \times 10^{16} \mathrm{Sr}^{+} / \mathrm{cm}^{2}$. The implanted samples were annealed in vacuum at temperature ranging from $23{ }^{\circ} \mathrm{C}-650{ }^{\circ} \mathrm{C}$ and in-situ real-time RBS analysis was carried out during the annealing process in order to investigate the diffusion behaviour of the implanted strontium. - The vacancy distribution profile derived from SRIM simulation shows that the radiation damage introduced by ion bombardment is concentrated towards the surface region of the glassy carbon substrate.

- During low temperature annealing, the Sr atoms moved deeper into the bulk of the glassy carbon substrate due to the presence of vacancy and interstitial defects in the surface region of the glassy carbon. Migration of the implanted Sr towards the surface of the glassy carbon was observed at temperatures ranging from $560{ }^{\circ} \mathrm{C}-650^{\circ} \mathrm{C}$.

- Migration of the implanted $\mathrm{Sr}$ towards the surface of the glassy carbon was observed at temperatures ranging from $560{ }^{\circ} \mathrm{C}-650{ }^{\circ} \mathrm{C}$. The migration towards the surface was accompanied with segregation of $\mathrm{Sr}$ towards the surface. The segregated strontium was retained on the glassy carbon substrate and no loss of strontium was recorded.

- The diffusion of Sr was limited to the damaged region of the glassy carbon and no diffusion into the pristine glassy carbon was observed. The results of the study show that glassy carbon is an excellent containment material for radioactive strontium.

\begin{abstract}
The diffusion behaviour of strontium in glassy carbon was investigated using in-situ real time Rutherford backscattering spectrometry. The sample was annealed in vacuum from room temperature to $650{ }^{\circ} \mathrm{C}$. Diffusion of the implanted strontium towards the bulk was observed after annealing at temperatures ranging from $450{ }^{\circ} \mathrm{C}-560{ }^{\circ} \mathrm{C}$. The diffusion depth was limited to the end-of-ion-range region where there were still some radiation damage present.
\end{abstract}


No diffusion into the pristine glassy carbon was observed suggestion that diffusion of $\mathrm{Sr}$ in glassy carbon can only occur in regions with radiation damage. Annealing the sample at higher temperatures higher than $560{ }^{\circ} \mathrm{C}$ resulted in migration of the implanted strontium towards the surface of the glassy carbon substrate. The amount of the accumulated strontium at the surface increased as the annealing temperature is increased. The RBS spectra obtained after annealing the sample isothermally at $650{ }^{\circ} \mathrm{C}$ for 2 hours show that there was no further diffusion and accumulation of the strontium during this period.

KEYWORDS: GLASSY CARBON, STRONTIUM, ION IMPLANTATION, IN-SITU RBS, VACUUM ANNEALING.

\section{INTRODUCTION}

The environmental implications of burning fossil fuels for power generation have been well documented. Due to these environmental problems, there has been a need for a cleaner and more environmentally friendly source of power. Wind, solar and nuclear energy are cleaner ways of power generation [1]. Nuclear energy is perhaps the least favored source of clean power generation out of the trio due to the problem of nuclear waste storage, management and safety [2]. Due to the increase in energy demand over the years, there has been a resurgence of nuclear energy around the world including Africa.

The storage of nuclear waste especially the high level waste (HLW) including ${ }^{239} \mathrm{Pu},{ }^{90} \mathrm{Sr}$, ${ }^{93} \mathrm{Zr}$ and ${ }^{107} \mathrm{Pd}$ has been a major concern for researchers. [3]. Nuclear waste is typically stored by putting it in pools that are at least 20 feet deep or by keeping them in dry cask storages [4]. The dry cask storage systems are typically made from materials such as copper, 
stainless steel and titanium alloys. The drawbacks of using these materials include brittleness, corrosion and cost.

In this study, our aim is to propose a new and more suitable material namely glassy carbon for constructing the dry cask storage. Glassy carbon (GC) is an advanced allotrope of carbon which combines the properties of glass, ceramic and graphite. It has been described to be a purely $\mathrm{sp}^{2}$ artificial carbon with superior features when compared to graphite [5]. Glassy carbon has been proposed as a favorable material for making nuclear storage cask because of the following properties: High temperature resistance, good corrosion resistance, hardness, strength and extremely high resistance to thermal shock $[6,7]$.

In order for glassy carbon to be a good storage material, it must also be a good diffusion barrier for fission products and its structure must remain unchanged so that it retains its properties even in extreme conditions.

This paper aims to investigate the diffusion behavior of strontium in glassy carbon using insitu and real time Rutherford backscattering spectrometry (RBS) during the heating process. Ion implantation was used to introduce strontium ions into the glassy carbon substrate. It was a preferred method in this study since the strontium depth profile and dosage could be controlled and monitored. Furthermore, it introduces radiation damage in the glassy carbon. For this project it is also important to investigate the diffusion of strontium in radiation damaged glassy carbon.

\section{EXPERIMENTAL PROCEDURE}

Commercial glassy carbon substrates were mechanically successively polished with $1 \mu \mathrm{m}$ and $0.5 \mu \mathrm{m}$ diamond solutions. The samples were cleaned and implanted with strontium ions by a 
$400 \mathrm{keV}$ ion implanter at room temperature and at energy of $200 \mathrm{keV}$ to a fluence of $1 \times 10^{16}$ ions $/ \mathrm{cm}^{2}$. The maximum concentration of strontium present in the glassy carbon substrate was calculated to be about $5 \%$. Because $\mathrm{Sr}$ forms a compound $\left(\mathrm{SrC}_{2}\right)$ with carbon, this concentration is below the solubility limit of $\mathrm{Sr}$ in glassy carbon.

The flux during implantation was kept at about $10^{13} \mathrm{~cm}^{-2} \mathrm{~s}^{-1}$ in order to keep the temperature during implantation low because of our interest in studying the effect of radiation damage on the diffusion of the implanted strontium.

Real-time RBS analysis was carried out in-situ in a vacuum chamber fitted with a copper heating stage. A thermocouple was attached to the vacuum system from the rear through a narrow hole in the copper heating stage so that the thermocouple tip was located exactly underneath the copper surface on which the sample was mounted. The thermocouple was calibrated by carrying out in-situ resistivity measurements. This was done by constructing a four-point probe made out of Ta wires. Resistance measurements were then carried out on $\mathrm{Au} / \mathrm{Si}$ samples. The surface temperature of the $\mathrm{Au} / \mathrm{Si}$ sample was measured as a function of the thermocouple temperature and the relationship between the measured temperature and the sample surface temperature was established. The temperature measured by the thermocouple was estimated to be less than $4{ }^{\circ} \mathrm{C}$ higher than that of the $\mathrm{Au} / \mathrm{Si}$ sample surface temperature.

The setup allowed for the sample to be annealed and analyzed simultaneously over a wide temperature range. The RBS spectra were acquired with $1.6 \mathrm{MeV} \mathrm{He}^{+}$particles at a backscattering angle of $165^{\circ}$ and the sample was tilted $10^{\circ}$ towards the detector. The depth resolution for a step-function profile was about $6 \mathrm{~nm}$. For a sloping profile, the resolution improves about an order of magnitude.

The temperature profile illustrated in Figure 1 show the annealing regime used in this study. Previous studies have shown that diffusion of the strontium implanted in the glassy carbon 
substrates only starts occurring at $300{ }^{\circ} \mathrm{C}[8,9]$. Therefore, the temperature of the sample was ramped quickly from room temperature to $300{ }^{\circ} \mathrm{C}$; this took about 20 minutes. After the quick ramp, the temperature was then increased by $2{ }^{\circ} \mathrm{C} /$ minute with the resulting RBS spectrum collected after every 2 minutes until the temperature rose to $650{ }^{\circ} \mathrm{C}$. Isothermal annealing was also carried out by keeping the temperature constant at $650^{\circ} \mathrm{C}$ for about 2 hours. The resulting RBS spectra are shown in Figure 2 (a) and 2(b) respectively. The selected spectra of interest were also fitted using a Gaussian equation fit. The fitted spectra heights, projected range $\left(R_{p}\right)$ and the straggling $\left(\Delta R_{p}\right)$ were plotted as a function of temperature.

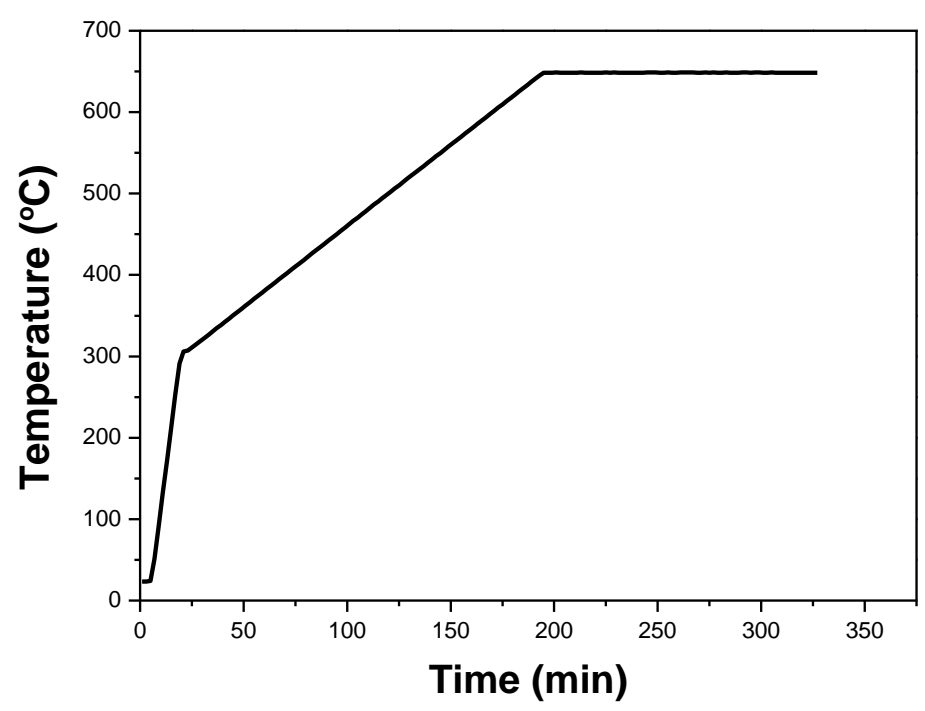

Figure 1: Graph showing the temperature profile during in-situ RBS analysis.

\section{RESULTS AND DISCUSSION}

The resulting real-time RBS spectra obtained throughout the experiment are shown as a contour plot and 3-dimensional plot in Figures 2(a) and 2(b) respectively. The contour plot gives a clear view on the diffusion behaviour of the implanted strontium. In the figure, four distinct bands which serve as representatives of the different ions in the system can be seen. 


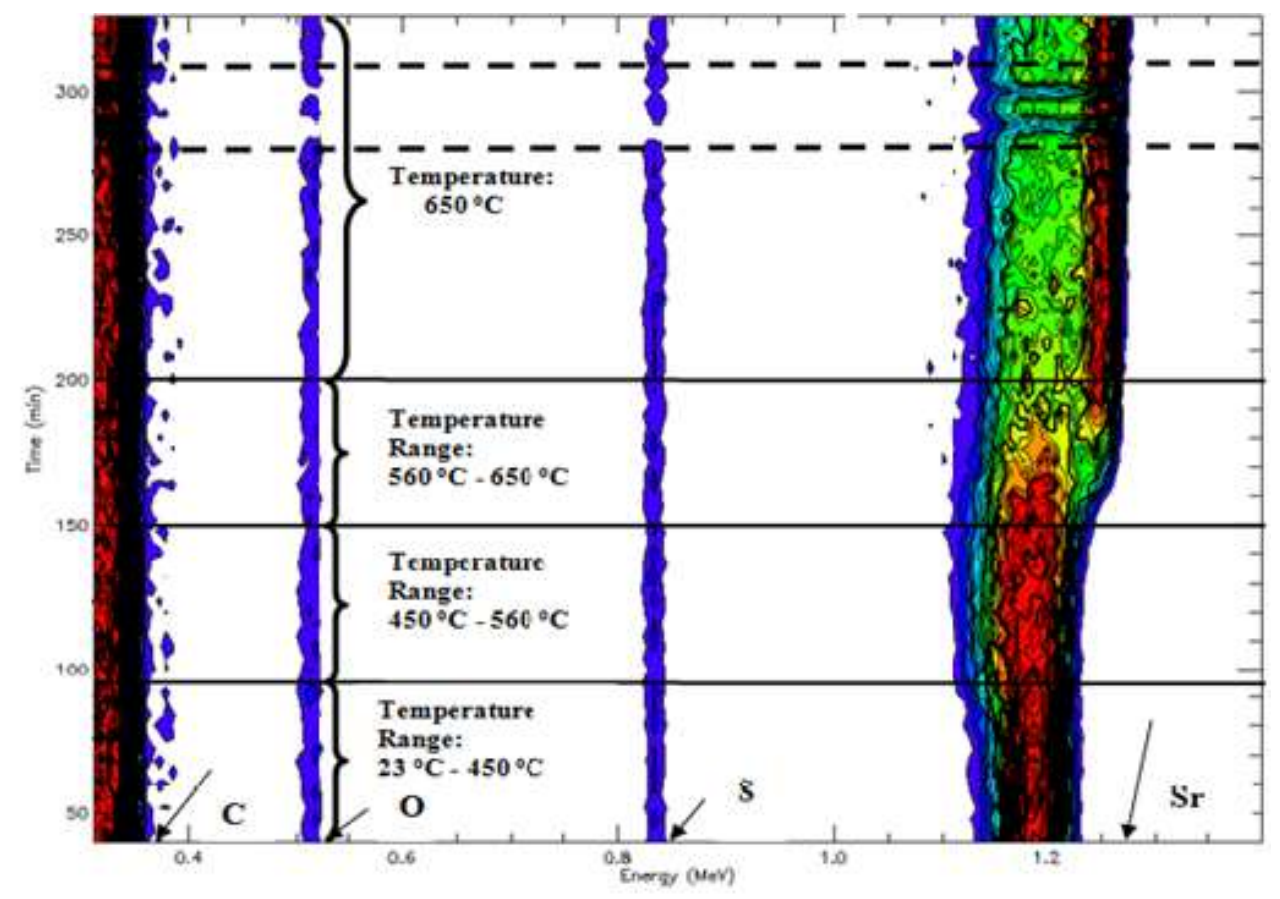

(a)

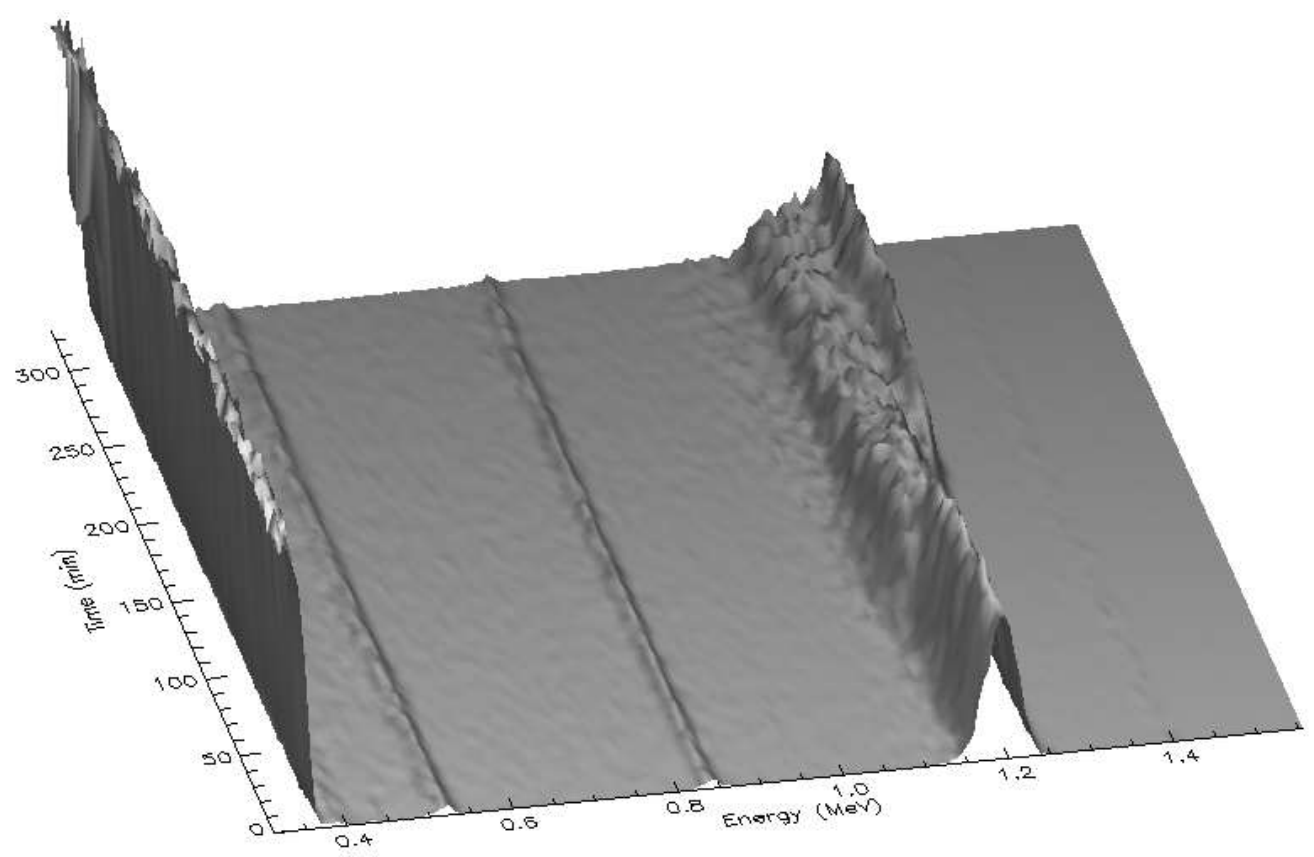

(b)

Figure 2. (a) Contour plot representation obtained during real-time RBS analysis. The vacuum annealing was carried out in-situ. The arrows indicate the surface channels for all the atomic species present. (b) 3-D overlay of spectra obtained during in-situ real time RBS analysis. 
The oxygen and sulphur lines that appear in the contour plots were also observed in a RBS measurement done on another virgin glassy carbon sample from the same batch obtained from the manufacturer. This suggests that they were present during the fabrication of the glassy carbon. The difference in the peak height is represented by different colours in the contour plot with red representing the areas with the highest counts and the green representing the area with the lowest counts. The yellow line is the intermediary height between the red and green lines. The contour plot also shows two dash lines which runs through the plot at 290 and 300 minutes respectively. At these times, the analysing charge was low, hence, the intensity of the RBS spectra recorded were low when compared to the other spectra.

The as-implanted depth profile was fitted with a Gaussian distribution and the projected range, $R_{p}$ and the straggling, $\Delta R_{p}$ were compared with those acquired from SRIM [10]. Using the density of Sigradur () G glassy carbon, i.e. $1.42 \mathrm{~g} / \mathrm{cm}^{3}$, the SRIM simulations predicted a projected range $R_{p}$ of $157 \mathrm{~nm}$ and straggling $\Delta R_{p}$ of $34.5 \mathrm{~nm}$. The $R_{p}$ value was experimentally calculated to be $165 \mathrm{~nm}$ while the $\Delta R_{\mathrm{p}}$ was $61 \mathrm{~nm}$. The large difference in the $\Delta \mathrm{R}_{\mathrm{p}}$ values suggests that a redistribution of the implanted strontium already took place during bombardment. The SRIM calculated projected range value for the vacancy distribution, viz. $R_{d}=123 \mathrm{~nm}$ (with $\Delta R_{d}=46 \mathrm{~nm}$ ) is significantly lower than the SRIM projected range for the Sr ions. This means that the radiation damage is concentrated towards the surface region of the glassy carbon substrate.

A key feature visible in Figure 2 is the fact that the $\mathrm{Sr}$ does not penetrate the glassy carbon beyond a depth of about $340 \mathrm{~nm}=\mathrm{R}_{\mathrm{p}}+3 \Delta \mathrm{R}_{\mathrm{p}}$. At this depth of $\mathrm{R}_{\mathrm{p}}+3 \Delta \mathrm{R}_{\mathrm{p}}$, the concentration of the implanted $\mathrm{Sr}$ atoms is about $1 \%$ of its peak concentration. Thus, it effectively represents the boundary between the radiation damaged glassy carbon and the pristine bulk. This non-penetration of $\mathrm{Sr}$ into pristine glassy carbon together with the segrational kind of 
diffusion of the implanted $\mathrm{Sr}$ atoms towards the surface at the higher annealing temperatures (to be discussed later) suggest that a prime factor to be considered is the Gibbs Free Energy of the system.

From Figure 2 (a) and (b), it was observed that a broadening of the implanted profile started taking place after the annealing temperature increased to about $450{ }^{\circ} \mathrm{C}$ at the $96^{\text {th }}$ minute of analysis. This led to a movement of $\mathrm{Sr}$ atoms deeper inside the glassy carbon as observed by the blue band in Figure 2(a) moving towards the left. However, as mentioned above, the $\mathrm{Sr}$ atoms never moved beyond the radiation damaged region in the glassy carbon into the pristine bulk. The movement of the implanted strontium into the bulk at these temperatures is probably due to the redistribution of defects present in the implanted layer of the glassy carbon. From Figure 3 (a) it can be seen that the shape of the $\mathrm{Sr}$ profile still remained Gaussian indicating that the diffusion was Fickian. This broadening of the Sr profile was accompanied by a gradual and slight movement (about $20 \mathrm{~nm}$ ) of the peak position deeper inside the substrate. Outward (i.e. towards the surface) diffusion of the implanted strontium was observed starting from the $150^{\text {th }}$ minute when the annealing temperature had reached 560 ${ }^{\circ} \mathrm{C}$. During high temperature annealing, the $\mathrm{Sr}$ atoms have enough kinetic energy which enables them to move towards the surface of the glassy carbon.

The redistribution of the implanted strontium can also be seen in the contour plot shown in Figure 2(a). A change in the contour colour within the strontium profile from red to yellow and green respectively shows that there was a decrease in the strontium peak height. This shows that there was broadening of the strontium peak after annealing. This broadening of the peak was accompanied by a change in the shape of the implanted profile (see Figures 2 (b) and (3). The profile is no longer Gaussian but becomes skewed towards the surface. At the highest annealing temperaure of $650{ }^{\circ} \mathrm{C}$ and long annealing times there is an accumulation of $\mathrm{Sr}$ on and in the surface region of the glassy carbon, i.e. a kind of 
segregation towards the surface. Although not a pure surface segregation process, it is probably also driven by a Gibbs free energy (or chemical potential) minimization process. The driving force for surface segregation is usually explained in terms of either atomic binding energy differences or/and strain reduction due to atomic size differences [12]. For the former one must consider the difference in the binding energy between the impurity and bulk (i.e. Sr-C) atoms and the binding energies of the pure components, i.e. the $\mathrm{C}-\mathrm{C}$ and $\mathrm{Sr}-\mathrm{Sr}$ bonds. The known strontium carbide $\mathrm{SrC}_{2}$ has a heat of formation energy of $\Delta \mathrm{H}_{\mathrm{f}}=-0.78 \mathrm{eV}$ [13]. Effectively, this means that $\mathrm{SrC}_{2}$ is not a very stable compound. This is confirmed by an experiment where $\mathrm{Sr}, \mathrm{U}$ and $\mathrm{C}$ pellets were mixed and heated at $1400{ }^{\circ} \mathrm{C}$ for $48 \mathrm{~h}$ [14]. With XRD analysis, only a very weak $\mathrm{SrC}_{2}$ signal was obtained, in contrast to the UC signal. The fact that there is diffusion of the $\mathrm{Sr}$ at low temperatures, as in our experiment, is further evidence of $\mathrm{SrC}_{2}$ is not a very stable compound. Thus, there would be very little difference between the chemical potential of the impurity implanted system and that of the segregated pure elements. The second mechanism for segregation is more convincing for our argument and uses the difference between the atom sizes. The much larger size of the $\mathrm{Sr}$ atom (atom radius of $215 \mathrm{pm}$ ) compared to the $\mathrm{C}$ atom (atom radius of $77 \mathrm{pm}$ ) can lead to significant strain in the implanted region of the glassy carbon. Thus, the combined effect of both these mechanisms may lead to the outwards diffusion of the $\mathrm{Sr}$ atoms from the glassy carbon substrate.

This accumulation of the implanted strontium can also be seen on the contour plot shown in figure 2 above with a red contour line appearing near the surface region. This signifies that there was an increase in the amount of strontium in this region.

The intensity of the accumulated strontium peak increases as the annealing temperature is increased from $620{ }^{\circ} \mathrm{C}-650{ }^{\circ} \mathrm{C}$. The accumulated strontium was retained on the glassy carbon substrate and no loss of strontium was recorded. This means that there was 
insignificant sublimation of the surface $\mathrm{Sr}$ atoms at these temperatures probably because these temperatures were lower than the melting point of strontium, i.e. $769{ }^{\circ} \mathrm{C}$.

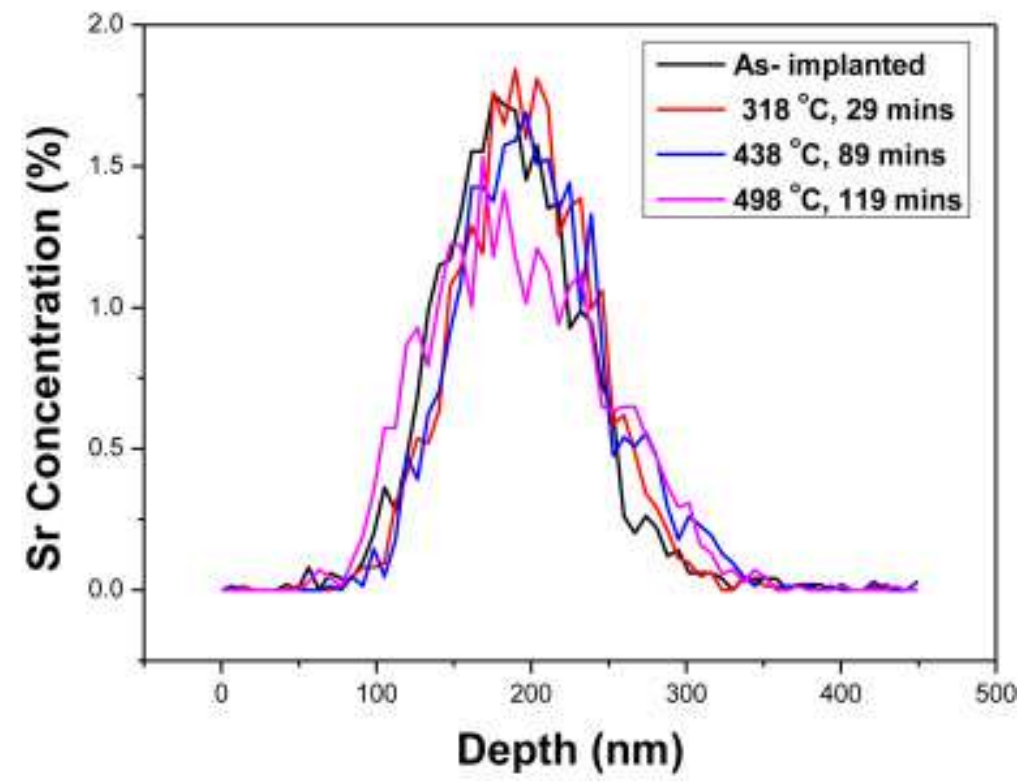

(a)

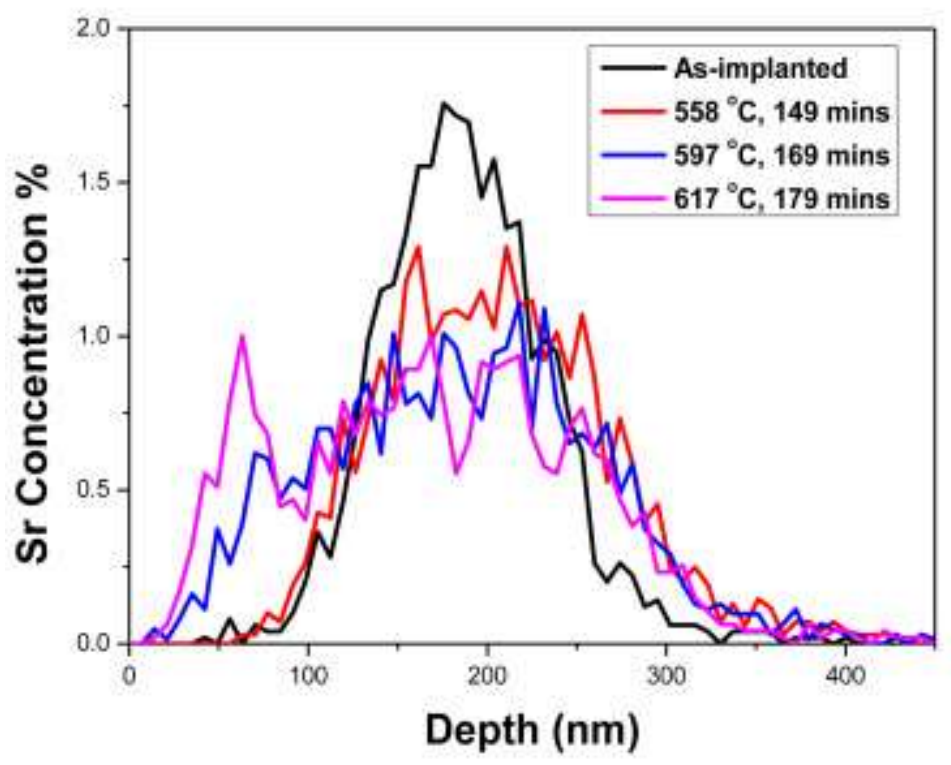

(b)

Figure 3(a) \& 3(b): RBS profile of the strontium peak obtained at different temperatures and time. 
Figure 4 illustrates the strontium peak height as a function of temperature. The peak heights were obtained by fitting all the acquired spectra to a Gaussian equation to obtain the first two moments, the projected range, $R_{p}$ and the range straggling, $\Delta R_{p}$. The peak heights in Figure 5 are the RBS values at Rp. The result shows that the peak height of the implanted strontium reduced after annealing the sample at temperatures higher than $400{ }^{\circ} \mathrm{C}$. The reduction in the peak height continued at higher temperatures with the number of counts reducing drastically to about 40 after annealing at $650{ }^{\circ} \mathrm{C}$. The reduction is due to a broadening (i.e. diffusion) of the $\mathrm{Sr}$ profile as discussed above.

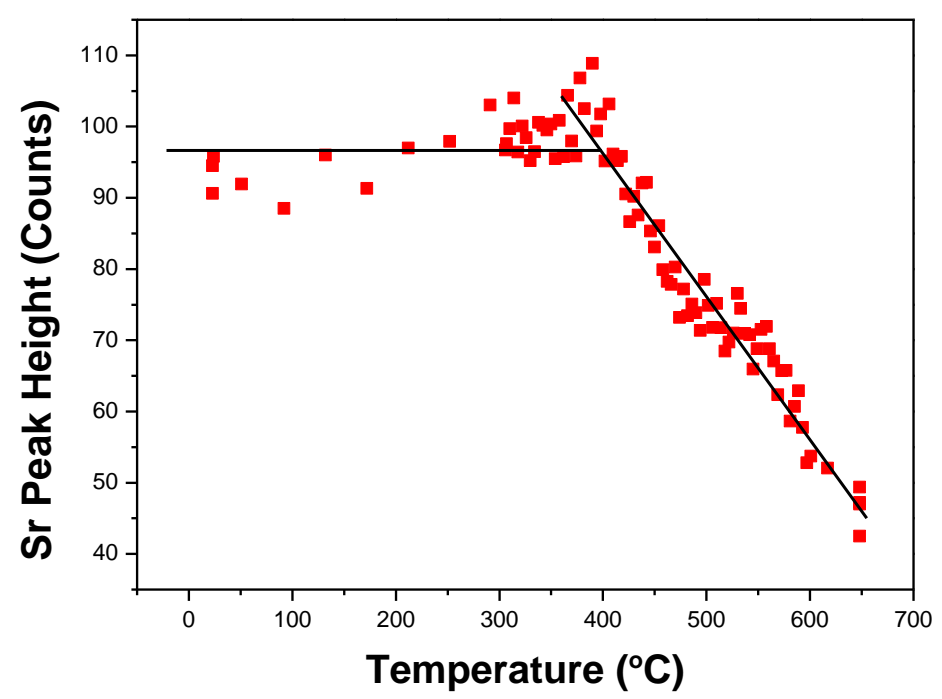

Figure 4: Strontium peak height obtained after fitting the acquired spectra with a Gaussian equation.

The projected range, $R_{p}$ and the straggling, $\Delta R_{p}$, have been used in several studies to monitor the diffusion pattern of ion implanted materials in different target materials [15-17]. In Figure 5 the projected range, $R_{p}$, is plotted as a function of annealing temperature. The $R_{p}$ values remained unchanged after annealing from temperatures ranging from $23{ }^{\circ} \mathrm{C}$ to about $450{ }^{\circ} \mathrm{C}$. There was an increase in the $\mathrm{R}_{\mathrm{p}}$ after annealing at temperatures ranging from $450{ }^{\circ} \mathrm{C}$ to about $560{ }^{\circ} \mathrm{C}$. The increase in the $\mathrm{R}_{\mathrm{p}}$ values can be attributed to the diffusion of the strontium into the bulk of the substrate. However, at higher temperatures, i.e. between 560 
${ }^{\circ} \mathrm{C}-650{ }^{\circ} \mathrm{C}$, the $\mathrm{R}_{\mathrm{p}}$ values reduced drastically. The reduction in the $\mathrm{R}_{\mathrm{p}}$ values can be attributed to the further segregation/diffusion of the strontium towards the surface. The spectra acquired at $620{ }^{\circ} \mathrm{C}$ to $650{ }^{\circ} \mathrm{C}$ were no longer symmetrical and could not be fitted accurately with the Gaussian equation that has been employed to fit the other spectra.

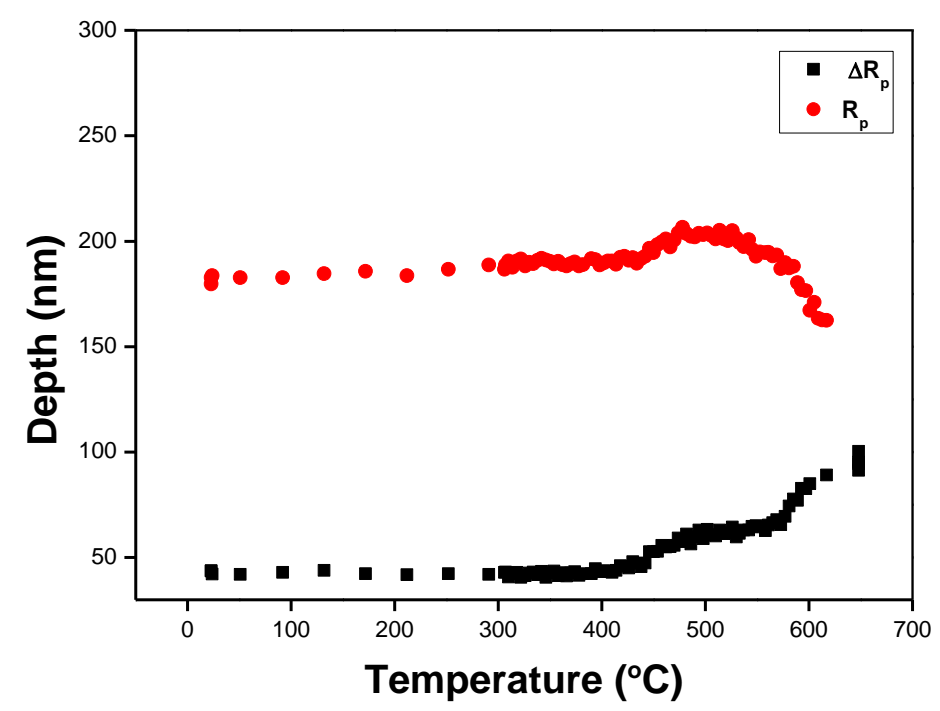

Figure 5: The effect of heat treatment on the projected range, $R_{p}$, and straggling, $\Delta R_{p}$, of strontium depth profiles.

An increase in the range straggling $\Delta R_{p}$ of the implanted profile is usually taken as a measure of diffusion of the implanted species $[15,16]$. From Figure 5 , it can be seen at temperatures ranging from $23{ }^{\circ} \mathrm{C}-450{ }^{\circ} \mathrm{C}$ that there was no change in the $\Delta \mathrm{R}_{\mathrm{p}}$ indicating no diffusion of the implanted strontium. The $\Delta \mathrm{R}_{\mathrm{p}}$ values obtained from $450{ }^{\circ} \mathrm{C}-650{ }^{\circ} \mathrm{C}$ show that two diffusion regimes occurred after heat treatment at this temperature range. The first regime occurred between $450{ }^{\circ} \mathrm{C}$ to about $620{ }^{\circ} \mathrm{C}$. Because there was Fickian diffusion of the implanted strontium into the bulk during this time interval, the $\Delta \mathrm{R}_{\mathrm{p}}$ values increased. As the annealing temperature is increased from $620{ }^{\circ} \mathrm{C}-650{ }^{\circ} \mathrm{C}$, there was sharp increase in the $\Delta \mathrm{R}_{\mathrm{p}}$ values. The increase in the $\Delta \mathrm{R}_{\mathrm{p}}$ values at these temperatures is due to the loss of symmetry in the strontium peak due to the accumulation of the implanted strontium on and near the 
surface of the glassy carbon. Those Sr profiles could no longer be fitted accurately with the Gaussian distribution equation.

Some isothermal annealing studies were also carried out at $650{ }^{\circ} \mathrm{C}$ for a total duration of 2 hours - see Figure 6. The resulting spectra observed during this time show that no further diffusion or accumulation of the implanted strontium took place. The similarity in the spectra obtained suggests that the diffusion of strontium in glassy carbon depends on the annealing temperatures with limited dependence on the annealing duration.

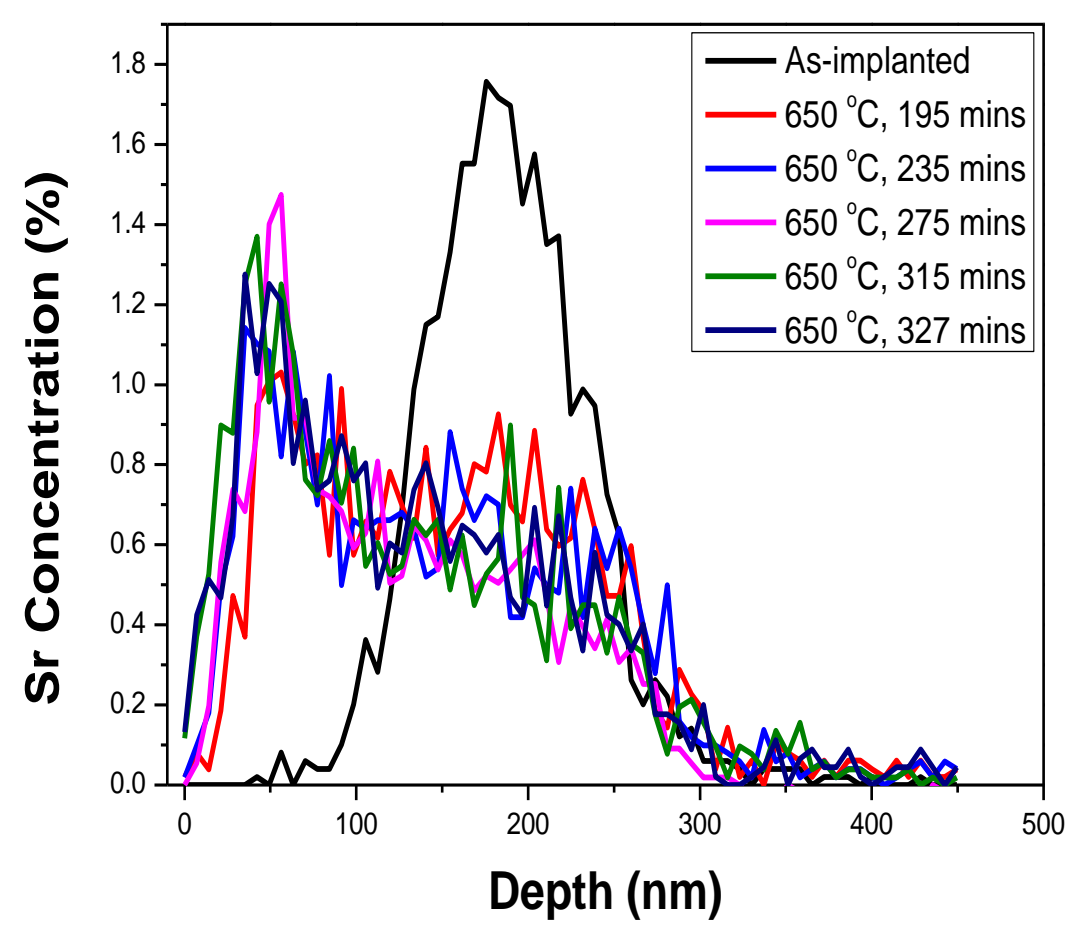

Figure 6: Some of the RBS spectra acquired after isothermal annealing at $650{ }^{\circ} \mathrm{C}$ (corresponding to a time of 195 minutes) for a period of 2 hours. Only the RBS profiles obtained after every 40 mins interval are shown. 


\section{CONCLUSION}

The effect of heat treatment on the diffusion behaviour of $200 \mathrm{keV}$ strontium implanted in glassy carbon at room temperature has been investigated using real-time in situ RBS studies.

The contour plot of the RBS spectra showed that diffusion of strontium towards the bulk of the glassy carbon substrate took place in temperature range of $450{ }^{\circ} \mathrm{C}-560{ }^{\circ} \mathrm{C}$. The diffusion of the Sr into the bulk after low temperature annealing was attributed to the redistribution of defects present in the implanted region of the glassy carbon. High temperature annealing resulted in migration of strontium towards the surface signified by the assymmetric broadening of the strontium profile. An additional peak was formed towards the surface (suggesting segregation) when the annealing temperature reached about $630{ }^{\circ} \mathrm{C}$. The segregation of strontium towards the surface of the glassy carbon was driven by a Gibbs Free Energy minimization process. There was no further diffusion observed during the 2 hours isothermal annealing at $650{ }^{\circ} \mathrm{C}$.

The progression of the projected range, $R_{p}$, and of the projected range straggling, $\Delta R_{p}$, as function of annealing temperature were both in agreement with the above diffusion results.

One of the most important practical finding in this study is the limitation of the diffusion of the strontium within the damaged region. This was attributed to the Gibbs Free Energy which prohibits the strontium atoms from diffusing into the pristine glassy carbon. The results of this study show that glassy carbon is an excellent containment material for radioactive strontium. 


\section{REFERENCES}

[1] Omer AM. A review of non-conventional energy systems and environmental pollution control. Journal of Soil Science and Environmental Management 2010;1:127-54.

[2] Hindmarsh R. Nuclear disaster at Fukushima Daiichi: social, political and environmental Issues. Routledge; 2013.

[3] Ewing RC, Weber WJ, Clinard FW. Radiation effects in nuclear waste forms for highlevel radioactive waste. Progress in Nuclear Energy 1995;29:63-127.

[4] world-nuclear.org. Radioactive Waste Management - Appendix 2: Storage and Disposal Options. Storage and Disposal Options 2010. http://worldnuclear.org/info/Nuclear-Fuel-Cycle/Nuclear-Wastes/Appendices/Radioactive-WasteManagement-Appendix-2--Storage-and-Disposal-Options (accessed June 14, 2013).

[5] Bukalov SS, Zubavichus YV, Leites LA, Sorokin AI, Kotosonov AS. Structural changes in industrial glassy carbon as a function of heat treatment temperature according to Raman Spectroscopy and X-ray diffraction data. Nanosystems: Physics, Chemistry, Mathematics 2014;5:186-91.

[6] Harris PJF. Fullerene-related structure of commercial glassy carbons. Philosophical Magazine 2004;84:3159-67. doi:10.1080/14786430410001720363.

[7] Pierson HO. Handbook of carbon, graphite, diamond and fullerenes. New Jersey: Noyes publications; 1993.

[8] Odutemowo OS. Modification of glassy carbon under strontium ion implantation.Masters Dissertation, University of Pretoria, 2013.

[9] Odutemowo OS, Malherbe JB, Prinsloo L, Langa DF, Wendler E. High temperature annealing studies of strontium ion implanted glassy carbon. Nuclear Instruments and Methods in Physics Research Section B: Beam Interactions with Materials and Atoms 2015.

[10] http://www.srim.org. Assessed on 25th November, 2015

[11] Odutemowo OS, Malherbe JB, Prinsloo L, Erasmus R, Wendler E. Investigating the structural changes in strontium implanted glassy carbon using multi-wavelength Raman Spectroscopy; To be Published

[12] Somorjai GA. Introduction to surface chemistry and catalysis. 1st ed.Chapter 3, John Wiley\& Sons, Inc.; 1994.

[13] Wagman DD, Evans WH, Parker VB, Schumm RH, Halow I. The NBS tables of chemical thermodynamic properties. Selected values for inorganic and C1 and C2 organic substances in SI units.70 ${ }^{\text {th }}$ Edition. CRC Press, Inc.; 1989. 
[14] Peatfield M, Brett NH, Potter PE. Constitutional studies on carbide nuclear fuels for fast breeder reactors: III. The uranium-barium-carbon ternary system at $1400^{\circ} \mathrm{C}$, with observations on the uranium-strontium-carbon system. Journal of Nuclear Materials 1980;89:35-40.

[15] Kuhudzai RJ, Friedland E, Malherbe JB, Theron C, van der Berg NG, Hlatshwayo TT, Wendler E. et al. Ion implantation of iodine in $6 \mathrm{H}-\mathrm{SiC}$, damage production and diffusion behaviour. Nuclear Instruments and Methods in Physics Research Section B: Beam Interactions with Materials and Atoms 2014;322:251-6.

[16] Hlatshwayo TT, Malherbe JB, van der Berg NG, Prinsloo LC, Botha AJ, Wendler E, et al. Annealing of silver implanted $6 \mathrm{H}--\mathrm{SiC}$ and the diffusion of the silver. Nuclear Instruments and Methods in Physics Research Section B: Beam Interactions with Materials and Atoms 2012;274:120-5.

[17] Friedland E, Malherbe JB, der Berg NG, Hlatshwayo T, Botha AJ, Wendler E, et al. Study of silver diffusion in silicon carbide. Journal of Nuclear Materials 2009;389:326-31. 